\title{
Connexin hemichannels and cell-cell channels: comparison of properties
}

V.K. Verselis,

E.B. Trexler and

F.F. Bukauskas
Department of Neuroscience, Albert Einstein College of Medicine, Bronx, NY, USA

\section{Correspondence \\ V.K. Verselis \\ Department of Neuroscience \\ Albert Einstein College of Medicine \\ Bronx, NY 10461 \\ USA \\ E-mail: verselis@ aecom.yu.edu \\ Presented at the Meeting \\ "Gap Junctions in the Nervous and \\ Cardiovascular Systems: Clinical \\ Implications", Rio de Janeiro, RJ, \\ Brazil, June 6-11, 1998.}

Received December 22, 1999

Accepted February 16, 2000

\section{Abstract}

Connexin46 (Cx46) forms functional hemichannels in the absence of contact by an apposed hemichannel and we have used these hemichannels to study gating and permeation at the single channel level with high time resolution. Using both cell-attached and -excised patch configurations, we find that single $\mathrm{Cx} 46$ hemichannels exhibit some properties expected of half of a gap junction channel, as well as novel properties. Cx46 hemichannels have a large unitary conductance $(\sim 300 \mathrm{pS})$ and a relatively large pore as inferred from permeability to TEA. Both monovalent cations and anions can permeate, but cations are substantially more permeable. The open channel conductance shows marked inward rectification in symmetric salts. We find that the conductance and permeability properties of $\mathrm{Cx} 46$ cell-cell channels can be explained by the series addition of two hemichannels. These data suggest that the pore structures of unapposed hemichannels and cell-cell channels are conserved. Also like cell-cell channels, unapposed Cx46 hemichannels are closed by elevated levels of $\mathrm{H}^{+}$or $\mathrm{Ca}^{2+}$ ions on the cytoplasmic face. Closure occurs in excised patches indicating that the actions of these agents do not require a soluble cytoplasmic factor. Fast $(<0.5 \mathrm{~ms})$ application of $\mathrm{H}^{+}$to either side of the open hemichannel causes an immediate small reduction in unitary conductance followed by complete closure with latencies that are dependent on $\mathrm{H}^{+}$concentration and side of application; sensitivity is much greater to $\mathrm{H}^{+}$on the cytoplasmic side. Closure by cytoplasmic $\mathrm{H}^{+}$does not require that the hemichannel be open. Thus, $\mathrm{H}^{+}$ions readily permeate $\mathrm{Cx} 46$ hemichannels, but at high enough concentration close them by acting at a cytoplasmic site(s) that causes a conformational change resulting in complete closure. Extracellular $\mathrm{H}^{+}$may permeate to act on the cytoplasmic site or act on a lower affinity extracellular site. Thus, the unapposed hemichannel is a valuable tool in addressing fundamental questions concerning the operation of gap junction channels that are difficult to answer by existing methods. The ability of $\mathrm{Cx} 46$, and perhaps other connexins, to form functional unapposed hemichannels that are opened by moderate depolarization may represent an unexplored role of connexins as mediators of transport across the plasma membrane.
Key words

- Permeability

- Channel gating

- Connexin46

- Patch clamp 


\section{Introduction}

The understanding of ion channel gating and permeation has been significantly advanced by the patch clamp technique by enabling recordings of amplitudes and dwell times of single channels. Together with exogenous expression of genetically altered channel proteins, the patch clamp has been instrumental in studies that have identified pore-lining and voltage-gating domains for a variety of channels. Unfortunately, it has not been possible to patch directly onto junctional membranes containing gap junction (GJ) channels formed of connexins. As an alternative means of recording single GJ channels, the double whole-cell patch technique has been applied $(1,2)$, but this technique can only be used with small cells and pharmacological intervention with uncouplers is often needed to reduce the number of channels between cells to a level that enables visualization of unitary currents. Additional drawbacks to the dual whole-cell technique are that the long-term stability of recordings has been insufficient to permit quantitative analysis of channel dwell times and that membrane capacity inherent to wholecell patch clamping decreases the frequency response well below that possible with excised patches containing one or several channels.

Macroscopic currents obtained from Xenopus oocytes expressing rat connexin 46 (Cx46) suggested that some connexins could function as hemichannels $(3,4)$. We reported that recordings of single $\mathrm{Cx} 46$ hemichannels obtained by patching onto the surface membrane of Xenopus oocytes expressing $\mathrm{Cx} 46$ could be obtained with regularity (5). Furthermore, we demonstrated that membrane patches containing hemichannels could be excised in inside-out and outside-out configurations, thus permitting exposure of the cytoplasmic and extracellular faces of the hemichannel to rapid, multiple and uniform solution exchanges. The utility of the hemichannel preparation has provided a new avenue with which to study GJ channels and the number of studies utilizing hemichannels has risen sharply over the last couple of years. Connexin structure-function is now being examined using hemichannels, as are mechanisms of connexin-based disease and GJ channel modulation. The caveat, of course, is that hemichannels are not cell-cell channels and it is important to relate findings obtained using hemichannels back to cellcell channels. In this article, we compare hemichannels and cell-cell channels formed of Cx46 and focus on two properties, ionic permeability and chemical gating by $\mathrm{H}^{+}$, to demonstrate similarities and differences.

\section{Conductance and permeability of Cx46 hemichannels and cell-cell channels}

Shown in Figure 1A are examples of recordings of macroscopic currents obtained by two-electrode voltage clamp and of single hemichannel currents obtained by patch clamp (cell-attached) from Xenopus oocytes expressing Cx46. Activation of $\mathrm{Cx} 46$ hemichannels in the oocyte membrane is characterized by a large, slowly rising current that is outward at inside positive voltage. Low extracellular $\mathrm{Ca}^{2+}$ enhances $\mathrm{Cx} 46$ hemichannel currents and significantly shifts activation in the hyperpolarizing direction (3). With sufficient levels of expression, patches containing single hemichannels can be routinely obtained as shown in the cell-attached recording. The unitary conductance of $\mathrm{Cx} 46$ hemichannels exceeds $300 \mathrm{pS}$ with solutions at physiological concentrations.

We excised patches containing single hemichannels and exposed them to solutions differing in composition to examine hemichannel conductance and permeability (Figure 1B). Shown are examples of I-V curves obtained by applying slow $(8 \mathrm{~s})$ voltage ramps to an excised, inside-out patch containing a single $\mathrm{Cx} 46$ hemichannel in symmetric $\mathrm{KCl}$, 
in a 5:1 $\mathrm{KCl}$ salt gradient and in a bi-ionic condition in which TMACl was substituted for $\mathrm{KCl}$ on one side. The patch pipette and perfusion solutions contained $\mathrm{Ca}^{2+} /$ EGTA so that the hemichannels opened over a wide voltage range. Solutions were switched using a multi-barreled rapid-exchange system as diagramed to the right (see also Ref. 6). A notable property of the $\mathrm{Cx} 46$ hemichannel is strong inward rectification of the open hemichannel current in symmetric $\mathrm{KCl}$. A $\mathrm{KCl}$ salt gradient shifted the reversal potential $\left(E_{\text {rev }}\right)$ negative on the side with the higher concentration, indicating strong ( 10:1) preference for $\mathrm{K}^{+}$over $\mathrm{Cl}^{-}$. Permeability ratios for the series of alkali metal cations were obtained with the appropriate bionic substitutions and assuming a $\mathrm{P}_{\mathrm{K}}: \mathrm{P}_{\mathrm{Cl}}$ ratio of 10:1. The cation selectivity sequence was found to be $\mathrm{Cs}^{+}>\mathrm{K}^{+}>\mathrm{Na}^{+}>\mathrm{Li}^{+}>\mathrm{TMA}^{+}>\mathrm{TEA}^{+}$with permeability ratios relative to $\mathrm{K}^{+}$of 1.19 : 1.00:0.80:0.64:0.34:0.20 (5). As expected for a large aqueous channel, the alkali cation permeability sequence was in order of their aqueous mobilities, but the permeabilities of the organic cations TMA and TEA were reduced more than expected, perhaps due to interactions with the channel wall. Anion permeabilities were low and their small contribution to $\mathrm{E}_{\text {rev }}$ did not allow reliable discrimination among the anions $\mathrm{Cl}^{-}, \mathrm{Br}^{-}$, $\mathrm{NO}_{3}{ }^{-}$, and acetate ${ }^{-}$. Inward rectification and
A

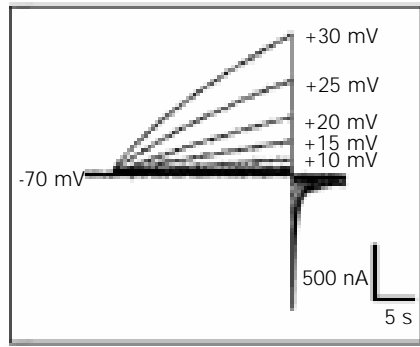

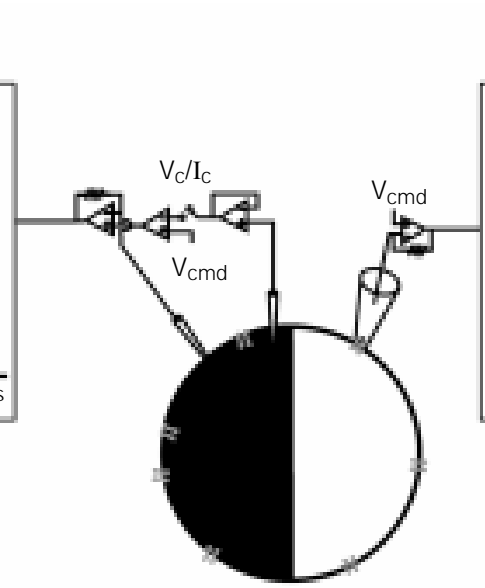

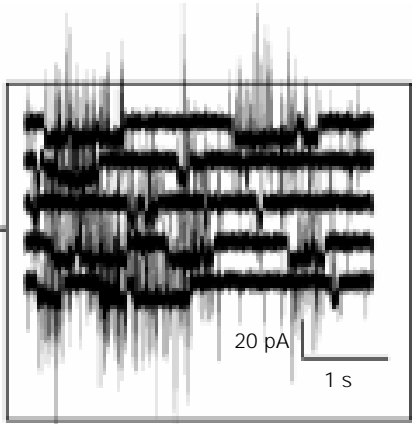

B
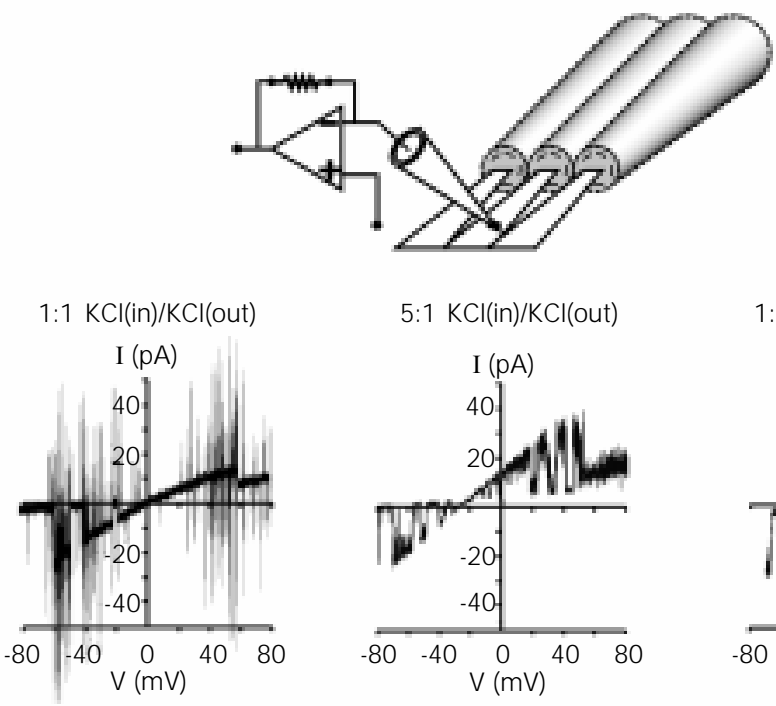

1:1 TMACl(in)/KCl(out)

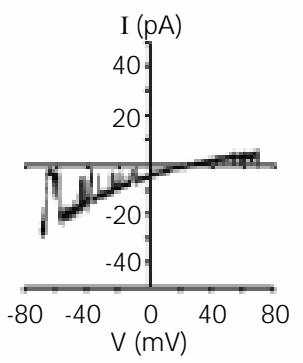

Figure 1 - Hemichannels provide a means of studying connexin properties. A, Examples of macroscopic and single channel recordings of $\mathrm{Cx} 46$ currents from Xenopus oocytes. B, Conductance and permeability can be examined rigorously using excised patches. A schematic drawing shows a multi-barrel perfusion system that was used to change solutions applied to excised patches containing hemichannels. Examples of recordings in symmetric and asymmetric conditions show changes in open channel I-V relations and shifts in reversal potential consistent with $\mathrm{Cx} 46$ hemichannels being cation selective. 
cation selectivity can be explained by the presence of fixed negative charges toward the extracellular end of the unapposed hemichannel (Trexler EB and Verselis VK, unpublished results).

Do conductance and permselectivity determined for unapposed $\mathrm{Cx} 46$ hemichannels predict $\mathrm{Cx} 46$ cell-cell channel properties? Structural rearrangements associated with hemichannel docking could conceivably change the properties of the pore. To qualitatively assess charge selectivity in $\mathrm{Cx} 46$ cellcell channels, HeLa and Neuro-2a cells were transfected with $\mathrm{Cx} 46$ and tracer flux was examined using Lucifer yellow (LY), a negatively charged dye, and 4',6-diamidino-2phenylindole, dihydrochloride (DAPI), a positively charged dye (Figure 2 ). These experiments used cell pairs so that $\mathrm{g}_{\mathrm{j}}$ could be assessed using dual whole-cell voltage clamp. In each experiment, a whole-cell recording was established in the donor cell (pipette with tracer) and a cell-attached recording was initially established in the recipient cell to prevent tracer loss due to dialysis with the patch pipette. Tracer spread was monitored by imaging over a period of 3-5 min, after which a whole-cell recording was established in the recipient cell to measure $\mathrm{g}_{\mathrm{j}}$. In all $\mathrm{Cx} 46$ cell pairs examined in which coupling exceeded $10 \mathrm{nS}$ there was no spread of LY. Conversely, DAPI spread in all cell pairs with comparable levels of coupling. DAPI

Figure 2 - Dye transfer suggests that $\mathrm{Cx} 46$ cell-cell channels are cation selective. Neuro-2a cell pairs transfected with $\mathrm{C} \times 46$ show transfer of DAPI, a positively charged dye, but not Lucifer yellow, a negatively charged dye. Cx43-transfected cell pairs readily transfer both DAPI and Lucifer yellow. J unctional conductance exceeded 20 nS in all cell pairs.
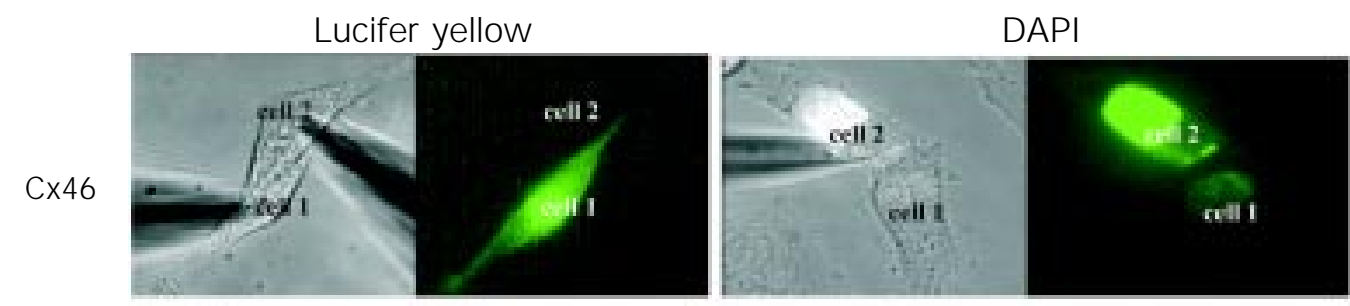

Cx43

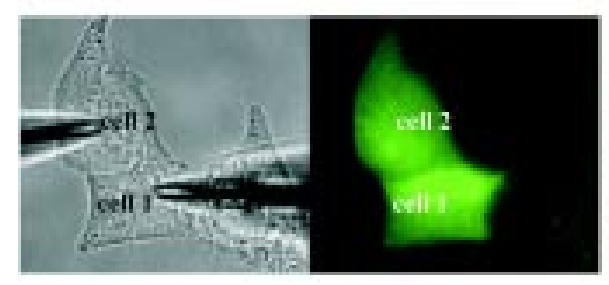

exhibits cytoplasmic and nuclear binding and requires that the site of tracer loading be close to the junctional membrane; intercellular spread was detected as DAPI stained the nucleus of the recipient cell. Using the same procedures, cell pairs expressing $\mathrm{Cx} 43$ showed strong LY transfer, in agreement with a number of published reports. DAPI was also permeable to $\mathrm{Cx} 43$, consistent with a poor selectivity on the basis of charge.

Fluorescent dyes are large molecules that differ considerably in size and chemical structure (e.g., LY has a MW of 453 and DAPI is 350). Thus, dye spread between cells, or lack thereof, can be influenced by many factors and we sought to assess charge selectivity of $\mathrm{Cx} 46$ cell-cell channels by measuring $\mathrm{E}_{\mathrm{rev}}$ in single salt gradients. Determining permeability by measuring $E_{\text {rev }}$ is technically very difficult, with problems that include accounting for offsets generated by two different pipette solutions, mixing of gradients between cells, and assessment of the baseline current at which the current reversal is to be measured. In dual whole-cell clamp, cell pairs are voltage-clamped independently (represented by batteries $\mathrm{V}_{1}$ and $\mathrm{V}_{2}$ in equivalent circuit of Figure $3 \mathrm{~A}$ ). $\mathrm{g}_{1}$ and $\mathrm{g}_{2}$ represent the input conductances of the cells. In the absence of coupling, the holding currents for each clamped cell are determined by their respective input conductances. The appearance of coupling mediated by GJs introduces 
Figure 3 - Selectivity of cell-cell channels measured using the technique of placing cells into contact while recording. A, Equivalent circuit representing a single cell pair in uncoupled (left) and coupled conditions (right). Conductances and associated batteries are indicated for each cell membrane and the junctional membrane. B, Records showing measurement of reversal potential $\left(E_{\text {rev }}\right)$ in cell pairs in a $3: 1 \mathrm{KCl}$ gradient. The appearance of a Cx46 cell-cell channel shifts holding current $\sim-18 \mathrm{mV}$, indicating cation selectivity (top records). The single channel I-V relation rectifies accordingly. No shift is seen with the appearance of a $\mathrm{C} \times 43$ cell-cell channel; the single channel I-V relation is linear. The pulse protocol consisted of $\pm 70 \mathrm{mV} \mathrm{V}$ ramps, $2.5 \mathrm{~s}$ in duration applied at regular intervals preceded by brief $(250 \mathrm{~ms}) \pm 20 \mathrm{mV} \mathrm{V}$ steps. The first arrow in both traces indicates opening of the first channel. A spontaneous closure is observed in the Cx46 cell-cell channel.

a battery between the cells, $E_{j}$, even in the absence of an applied $V_{j}$, if the salt composition differs in the two cells and the GJ channels are selective. This condition generates equal and opposite current flows in the clamps, thereby shifting both holding currents. Thus, when applying voltages to one cell to measure junctional current, $I_{j}$, defined as the current supplied by the clamp in the unstepped cell that is needed to maintain voltage constant, reversal of $I_{j}$ occurs when it crosses the value of the holding current of that cell in the absence of coupling. However, the holding currents in the absence of coupling are difficult to measure as it is infrequent that cell pairs are coupled by few GJ channels and the channels rarely close completely. We resolve these problems by employing the method of pairing cells while recording (7). In essence, cells are loosened from cover slips with a gentle stream of bath solution, individually patch clamped and placed into contact. Coupling typically develops within 15-20 min of contact, with the appearance of a single channel, followed several minutes later by a second and so on. Holding currents in each cell in the absence of coupling can be assessed just prior to the appearance of the first channel. With a single channel connecting two cells, mixing of gra-
A

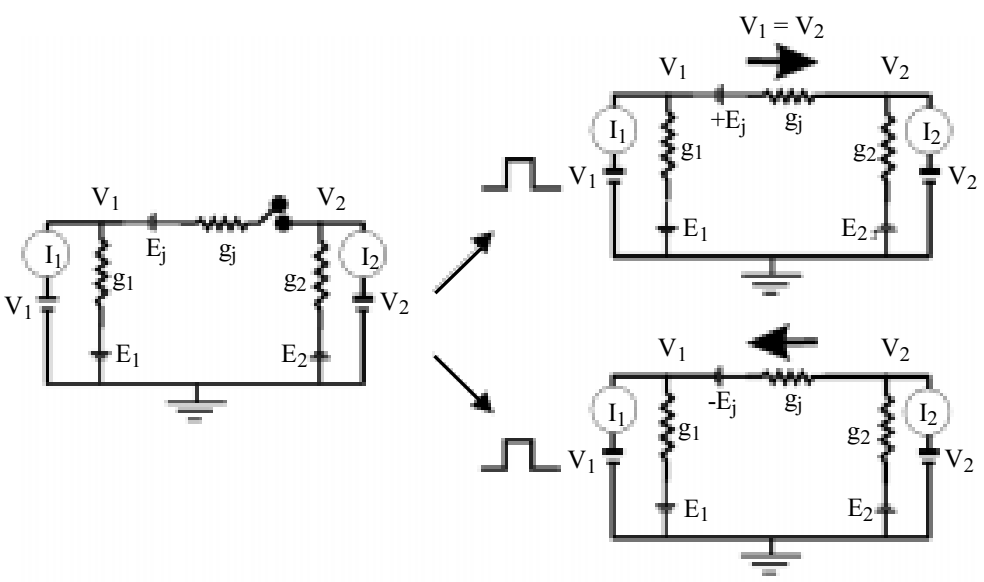

B
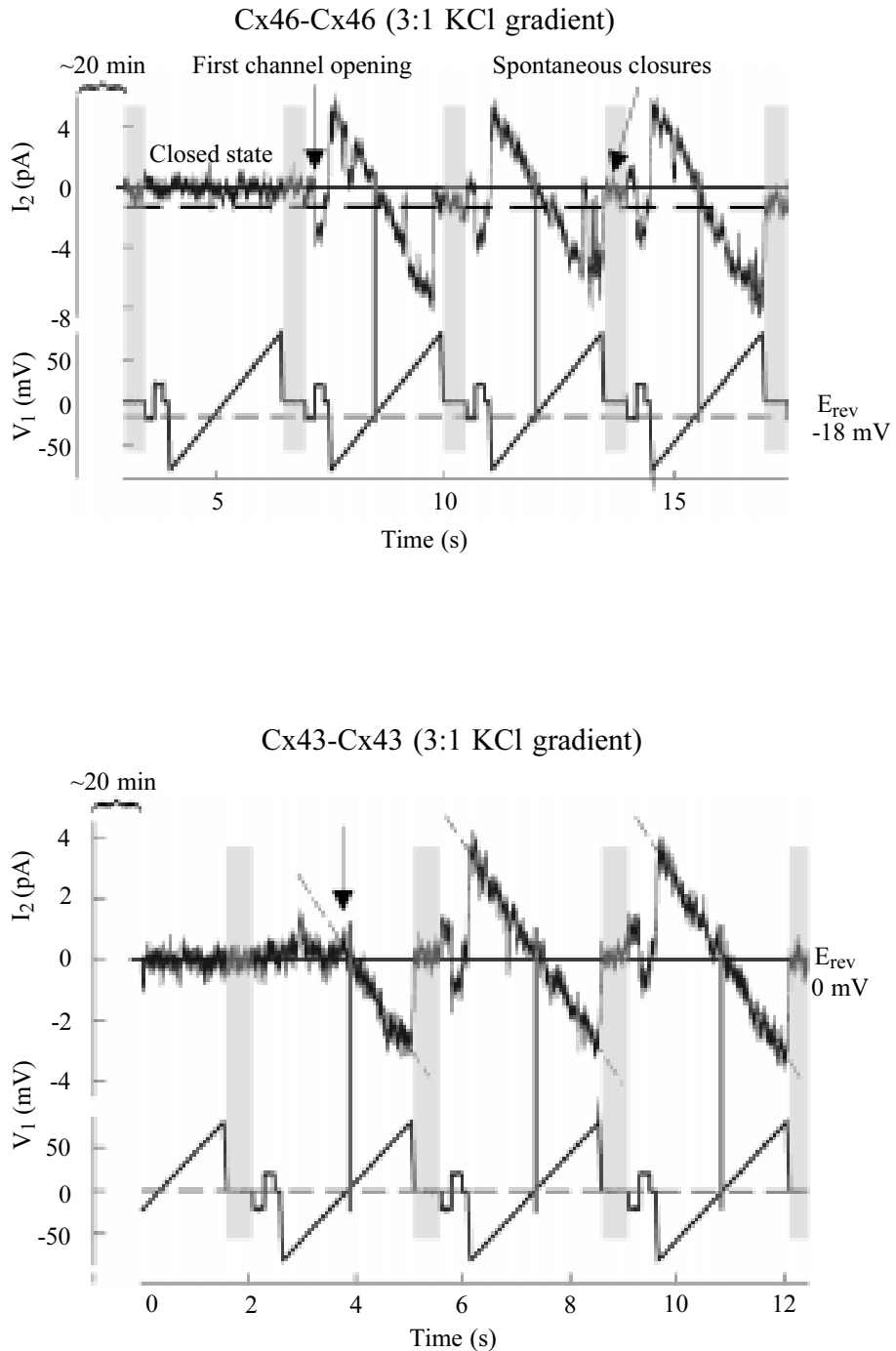
dients is negligible.

The use of this technique to measure conductance and selectivity in $\mathrm{Cx} 46$ and $\mathrm{Cx} 43$ cell-cell channels is illustrated in Figure 3B. Individual cells were whole-cell clamped and placed into contact $\sim 20 \mathrm{~min}$ prior to the time series shown. A voltage protocol was applied to cell 1 and consisted of a repeated series of $\pm 20 \mathrm{mV}$ steps $(250 \mathrm{~ms}$ in duration) followed by $\mathrm{a} \pm 70 \mathrm{mV} \operatorname{ramp}(2.5$ s). Patch pipettes differed $3: 1$ in $\mathrm{KCl}$ concentration for cell 1 :cell 2 . Iso-osmotic conditions were maintained with PEG200. In the $\mathrm{Cx} 43$ cell pair, the appearance of a channel caused no shift in holding current in the unstepped cell, $\mathrm{I}_{2}$, consistent with a lack of charge selectivity between $\mathrm{K}^{+}$and $\mathrm{Cl}^{-}\left(\mathrm{E}_{\mathrm{rev}} \approx\right.$ 0 , shaded bars are when $\mathrm{V}_{1}=\mathrm{V}_{2}$ ). Also consistent with a lack of selectivity was a linear single channel I-V curve in the presence of a salt gradient. When placing two Cx46-expressing cells into contact, the appearance of a channel shifted holding current giving $E_{\text {rev }}=-18 \mathrm{mV}$ and a calculated $\mathrm{P}_{\mathrm{K}}: \mathrm{P}_{\mathrm{Cl}} \sim 8$ (using the Goldman-Hodgkin-Katz voltage equation). The single channel $\mathrm{I}-\mathrm{V}$ curve for $\mathrm{Cx} 46$ rectified accordingly, i.e., with a larger current when the high side was made relatively positive. We also applied this technique to measure relative cation selectivity under bi-ionic conditions. We found it to be the same as in unapposed hemichannels, $\mathrm{K}^{+}>\mathrm{Na}^{+}>\mathrm{Li}^{+}>>\mathrm{TMA}^{+}>\mathrm{TEA}^{+}$. Thus, Cx46 channels, like hemichannels, maintain cation selectivity in order of bulk solution mobility and display reduced permeability to the organic cations $\mathrm{TMA}^{+}$and TEA $^{+}$.

$\mathrm{Cx} 46$ channels in symmetric $\mathrm{KCl}$ show a linear single open channel I-V relation giving a conductance of $140 \mathrm{pS}$, which is nearly half the hemichannel conductance when measured near $\mathrm{V}_{\mathrm{m}}=0(\sim 300 \mathrm{pS})$. Thus, conductance of the $\mathrm{Cx} 46$ cell-cell channel is close to that predicted for two hemichannels in series. However, linearity of the open channel I-V relation contrasts the strongly, inwardly rectifying hemichannels. This difference between hemichannels and cell-cell channels can be explained by a change in the relative placement of fixed negative charges upon docking of hemichannels. Docking via the extracellular loops would place charges located at the extracellular end of each hemichannel near the center of the cell-cell channel. When modeled with simplified continuum models (see Refs. 8,9) such shifts in relative charge placement could linearize the $\mathrm{I}-\mathrm{V}$ curve while maintaining charge selectivity.

\section{Chemical gating by $\mathrm{H}^{+}$in $\mathrm{Cx46}$ hemichannels and cell-cell channels}

Reduction in junctional conductance $\left(\mathrm{g}_{\mathrm{j}}\right)$ by intracellular acidification is common to both vertebrate and invertebrate GJs. Differences in $\mathrm{pH}$ sensitivity have been reported with apparent $\mathrm{pK}_{\mathrm{a}} \mathrm{s}$ ranging from about $\mathrm{pH} 6$ to 7.5 and both direct and indirect actions of $\mathrm{H}^{+}$have been proposed (reviewed in 10). However, studies of $\mathrm{pH}$ effects of GJ channels have been problematic because of an inability to rapidly and uniformly change intracellular $\mathrm{pH}\left(\mathrm{pH}_{\mathrm{i}}\right)$ and distinguish rapid direct effects from slower secondary, and perhaps indirect ones. Also, difficulties and differences in the methods of quantifying $\mathrm{pH}_{\mathrm{i}}$ and multiple connexin expression in native cells may have contributed to wide differences in reported $\mathrm{pH}$ sensitivities.

Connexin hemichannels in excised patches exposed to fast perfusion provide a means of examining the action of chemical modulators in a cell-free environment and with millisecond time resolution. Figure 4 shows a recording from an inside-out patch containing several active hemichannels placed in a solution at $\mathrm{pH} 7.5$. Switching to a $\mathrm{pH} 6.0$ solution led to rapid, complete and reversible closure of the hemichannels; an expanded view of one of these applications is shown below. A titration curve of the reduction in mean current by acidification 
generated from multiple excised patches could be fit by the Hill equation with an apparent $\mathrm{pK}_{\mathrm{a}}$ of 6.4 and an $n$ of 2.3. By virtue of the hemichannels being in an excised configuration, these results clearly demonstrate that no soluble cytoplasmic factors are required to cause acidification-induced closure.

We performed an ensemble analysis of currents from inside-out patches to examine the time course of closure with acidification. Sequential applications of low $\mathrm{pH}$ to a patch containing a single $\mathrm{Cx} 46$ hemichannel are shown in Figure 5A; the sum of these and over 100 more from 4 other patches containing multiple hemichannels is shown below. The decay in current reached a steady-state value ( $\sim 7 \%$ of control). The significance of the ensemble analysis is that the onset of the current decrease upon switching to low $\mathrm{pH}$ (dashed line) showed no measurable delay, which provides strong evidence that $\mathrm{H}^{+}$acts directly on $\mathrm{Cx} 46$ hemichannels. We also were able to show that the site of $\mathrm{H}^{+}$action is on the cytoplasmic side of the hemichannel by demonstrating that $\mathrm{H}^{+}$can act from the inside, but not from the outside, when the hemichannels are closed (data not shown; see Ref. 6).
Another feature of acidification-induced closure in $\mathrm{Cx} 46$ hemichannels was recovery that depended on the time of exposure to low $\mathrm{pH}$. Although currents fully recovered from multiple, successive 2-s acidifications, we observed less recovery when patches were acidified for longer times (Figure 5B). Ensemble currents normalized to the mean current at $\mathrm{pH} 7.5$ for 1-s, 2-s, and 5-s applications of $\mathrm{pH} 6.0$ solutions are superimposed. The initial current decay of all three followed nearly the same time course, but the degree of recovery from 5 -s applications was substantially reduced; $20 \%$ of the channels did not recover. With applications of 10 $s$ in duration, the degree of hemichannel loss in multichannel patches ranged from minimal to nearly $50 \%$.

A third feature of $\mathrm{H}^{+}$-induced closure in $\mathrm{Cx} 46$ hemichannels is that it occurs via transitions that are slow, often taking tens of milliseconds to complete. Shown in Figure $5 \mathrm{C}$ is an expanded time scale of a closing induced by $\mathrm{pH} 6.0$ application to a single Cx46 hemichannel. The closing transition fluctuated widely and took $\sim 100 \mathrm{~ms}$ to complete. After closing, there were additional small fluctuations that may represent partial reopenings. Although the time course of the

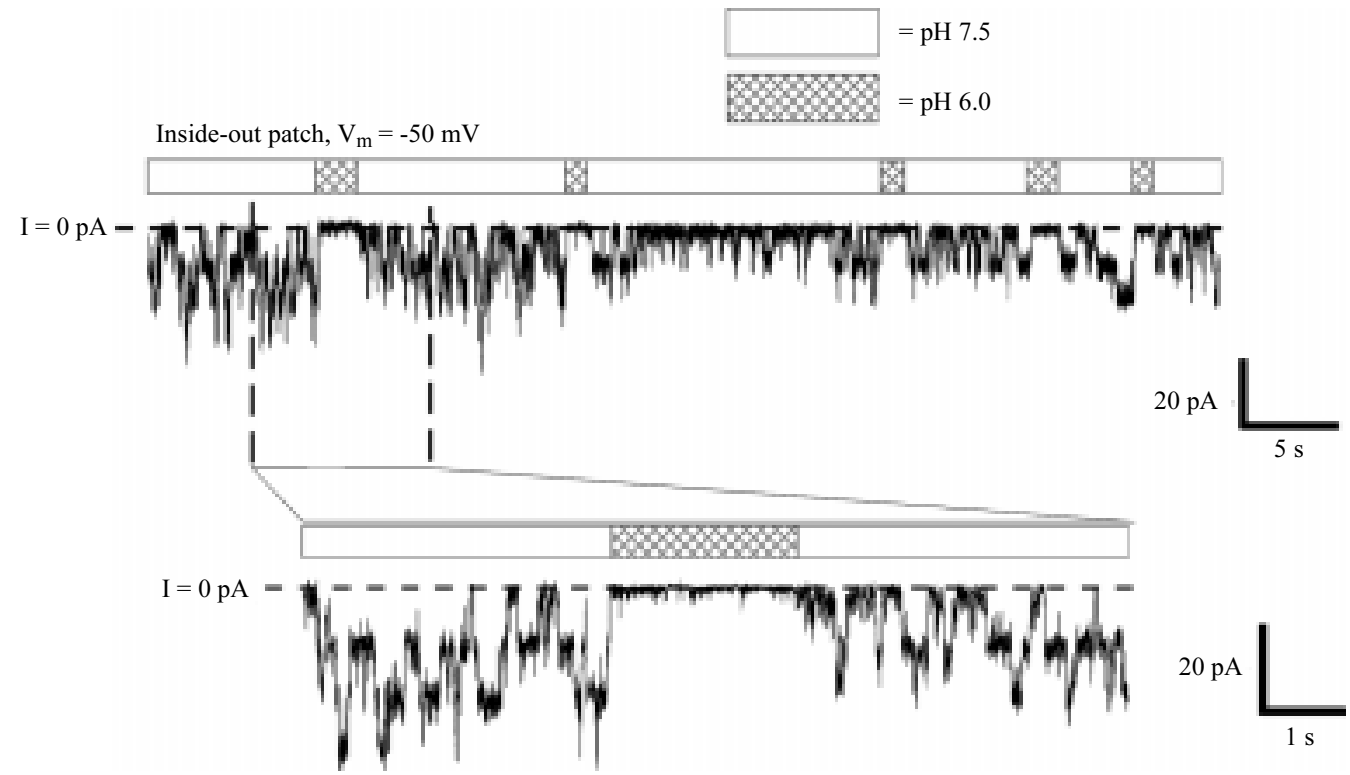

Figure 4 - Cx46 hemichannels in excised patches show sensitivity to $\mathrm{pH}$. An inside-out patch was placed in a solution stream at $\mathrm{pH} 7.5$ and rapidly switched to the same solution at 6.0. A sharp decrease in the open probability of the four active hemichannels in the patch is seen immediately upon switching to low $\mathrm{pH}$. Holding potential was $-50 \mathrm{mV}$; hemichannel openings are downward deflections in current. The expanded view of one application reveals the rapid closure of the channels and no openings for the duration of the low $\mathrm{pH}$ application. Upon switching back to $\mathrm{pH} 7.5$, the hemichannels returned to normal gating behavior. I = $0 \mathrm{pA}$ denotes the leak conductance of the patch. 
Figure 5 - The time course of $\mathrm{pH}$-induced closure. A, An inside-out patch containing a single Cx46 hemichannel was subjected to repeated applications of pH 6.0 (region within the rectangle). The duration of the low $\mathrm{pH}$ application was 2.0 $\mathrm{s}$. The beginning of each trace immediately follows the end of the previous trace. Hemichannel openings are downward deflections in current. The patch was held at $-30 \mathrm{mV}$. Below is a summation of the currents from this patch and with 122 more traces from 4 other patches at $-30 \mathrm{mV}$ containing multiple channels. There was no delay between $\mathrm{pH}$ 6.0 application and current decrease. B, Ensemble currents show the effect of the duration of acidification on the extent of recovery. Currents from multiple patches were normalized to the average of the currents over the $5 \mathrm{~s}$ before acidification. Recovery from 1- and 2-s applications is nearly $100 \%$, whereas recovery from 5-s applications is only $\sim 80 \%$. C, Transitions from fully open to fully closed states are slow for $\mathrm{pH}$-induced closures. Upon rapidly switching from $\mathrm{pH}$ 7.5 to $\mathrm{pH} 6.0$, closure required $>100 \mathrm{~ms}$ to complete. The full closing transition is very noisy with no clearly resolvable substates. Current idealization of the trace was obtained by using the Sublevel Hinkley detector (see 18,19). acidification-induced transitions varied from 20-100 ms, all hemichannel closures at low $\mathrm{pH}$ in both inside-out and outside-out configurations exhibited this slow gating between fully open and closed states.

How do the effects of $\mathrm{pH}$ on $\mathrm{Cx} 46$ hemichannels compare with those on $\mathrm{Cx} 46$ cellcell channels? It has been shown that gating of GJ channels by voltage is predominantly between the open state and a long-lived substate; the $\mathrm{V}_{\mathrm{j}}$ gating transitions are fast and typical of ion channel gating and complete closures are infrequent $(11,12)$. However, complete closures can be induced by exposure to chemical uncouplers, such as $\mathrm{H}^{+}$ or alkanols (13). The transitions associated with chemical gating are slow, taking tens of milliseconds to complete, are common to cell-cell channels formed of all connexins and resemble the gating transitions induced by low $\mathrm{pH}$ in $\mathrm{Cx} 46$ hemichannels.

Although we could not assess the kinetics of $\mathrm{H}^{+}$action due to limitations of intracellular perfusion, we could demonstrate that, like in $\mathrm{Cx} 46$ hemichannels, the site of action of $\mathrm{H}^{+}$in $\mathrm{Cx} 46$ cell-cell channels appears to be cytoplasmic. In pairs of Neuro-2a cells transfected with $\mathrm{Cx} 46$, we examined effects of $g_{j}$ with applications of bath solutions acidified by saturating with $\mathrm{CO}_{2}$ or by adding $\mathrm{HCl}$

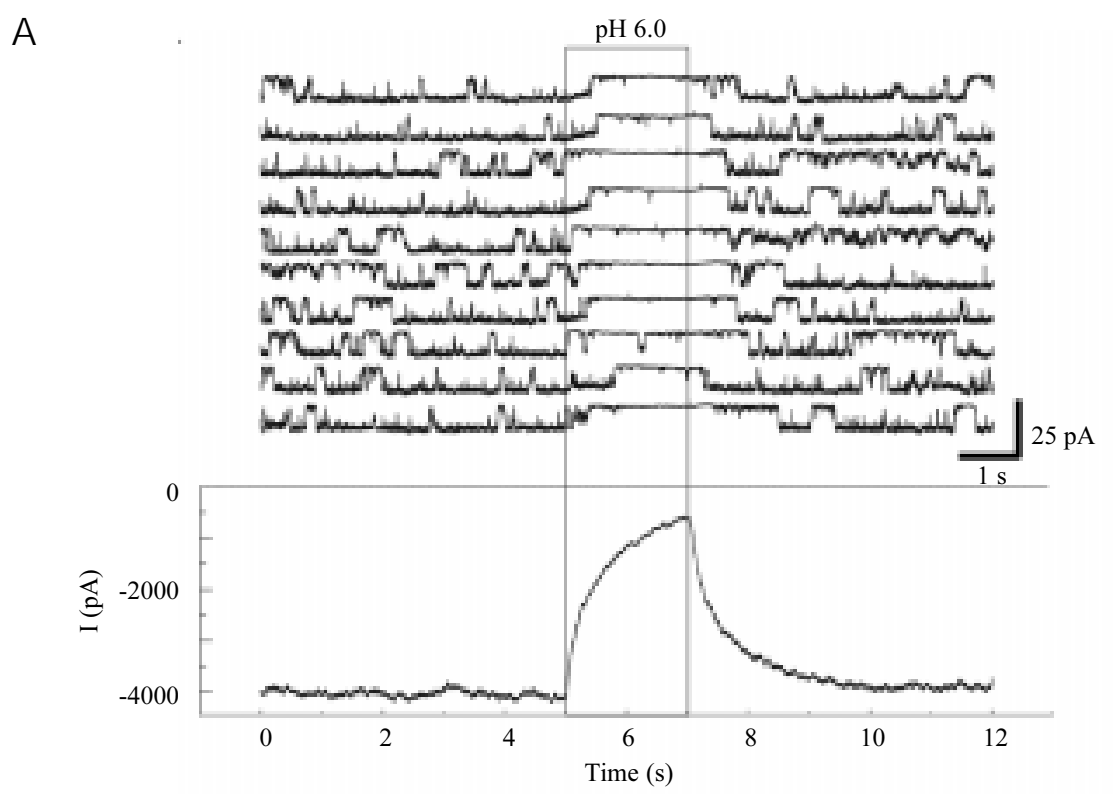

B

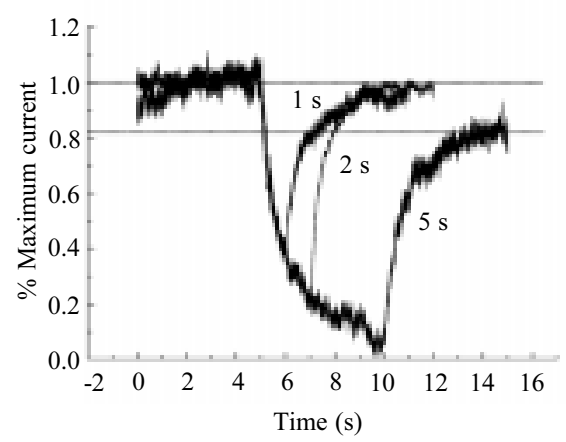

C

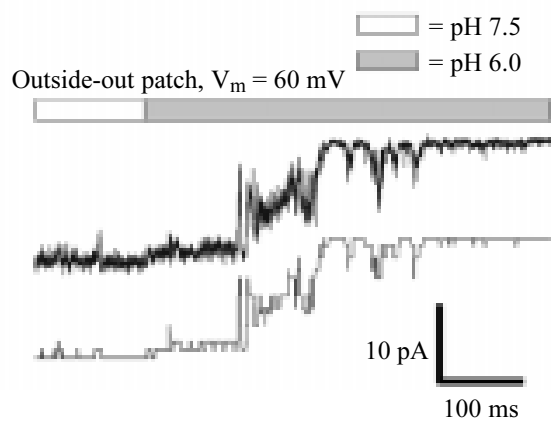


and buffering with combinations of HEPES and PIPES, presumably membrane impermeant buffers (Figure 6A). In general, the reductions in $g_{j}$ with applications of $\mathrm{HCl}$ acidified solutions differed from those caused by $100 \% \mathrm{CO}_{2}$ by being smaller in magnitude and slower to develop even when the $\mathrm{pH}$ of the $\mathrm{HCl}$-acidified solution was $\sim 5.5$, comparable to that of the $100 \% \mathrm{CO}_{2}$-equilibrated solution. To examine the extent and time course of the changes in $\mathrm{pH}_{\mathrm{i}}$ that occurred with application of $100 \% \mathrm{CO}_{2}$-acidified and $\mathrm{HCl}$-acidified solutions, we measured $\mathrm{pH}_{\mathrm{i}}$ using the $\mathrm{pH}$ indicator BCECF in separate Neuro-2a cells expressing Cx46 (Figure 6B). Reductions in $\mathrm{pH}_{\mathrm{i}}$ occurred with both treatments, but considerably more rapidly with $\mathrm{CO}_{2}$ application. Upon washing, $\mathrm{pH}_{\mathrm{i}}$ recovered slowly in both cases, but relatively faster with $\mathrm{HCl}$-acidified solutions. The general agreement between the degree and time course of the reversible changes in $\mathrm{g}_{\mathrm{j}}$ and in $\mathrm{pH}_{\mathrm{i}}$ are consistent with $\mathrm{pH}$ acting intracellularly, not extracellularly.

Also as demonstrated for $\mathrm{Cx} 46$ hemichannels, recovery from acidification-induced closure of $\mathrm{Cx} 46$ cell-cell channels depended on the time of exposure to low $\mathrm{pH}$. With a 45-s exposure to $\mathrm{CO}_{2}$ (Figure 6A, top trace), $I_{j}$ rapidly fell to below detectable levels and no recovery was detected for nearly $3 \mathrm{~min}$ after washout. Thereafter, $\mathrm{I}_{\mathrm{j}}$ slowly increased, but only reached a small fraction of the original value. In a different cell pair exposed to $\mathrm{CO}_{2}$ for shorter times of 25 and $15 \mathrm{~s}$ (Figure 7), $\mathrm{I}_{\mathrm{j}}$ rapidly declined, but recovered faster and to a greater degree; with the $\sim 15$-s exposure, $g_{j}$ made a nearly full recovery to the level prior to this exposure within several minutes. The dependence of recovery on the duration of exposure to $\mathrm{CO}_{2}$ was the same in cell pairs that were exposed to
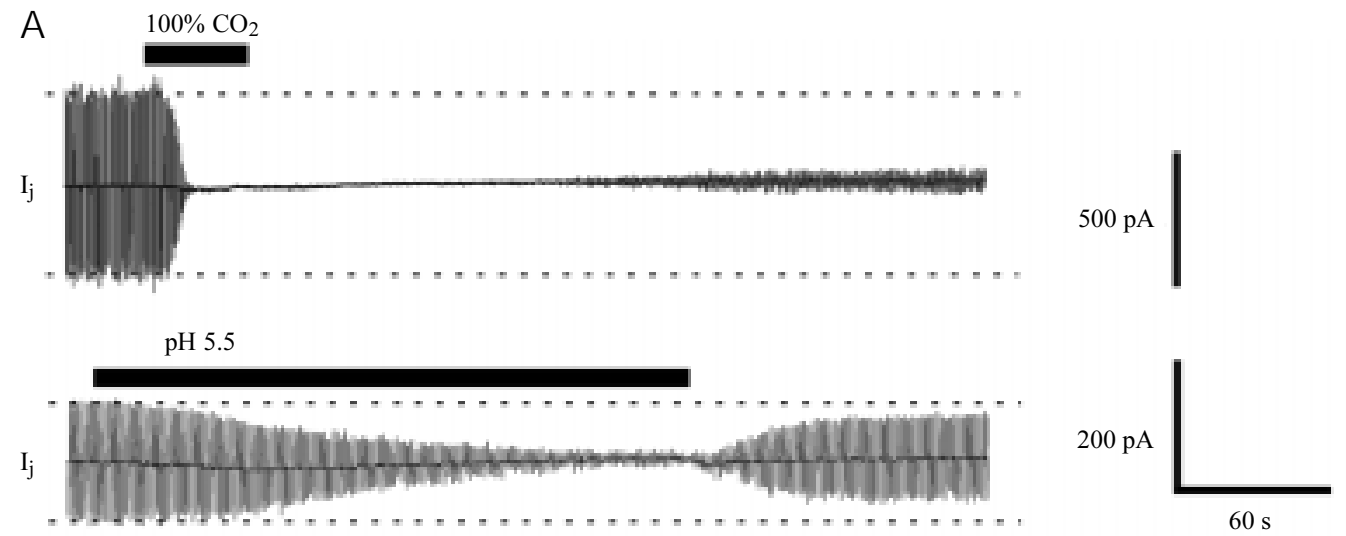

B
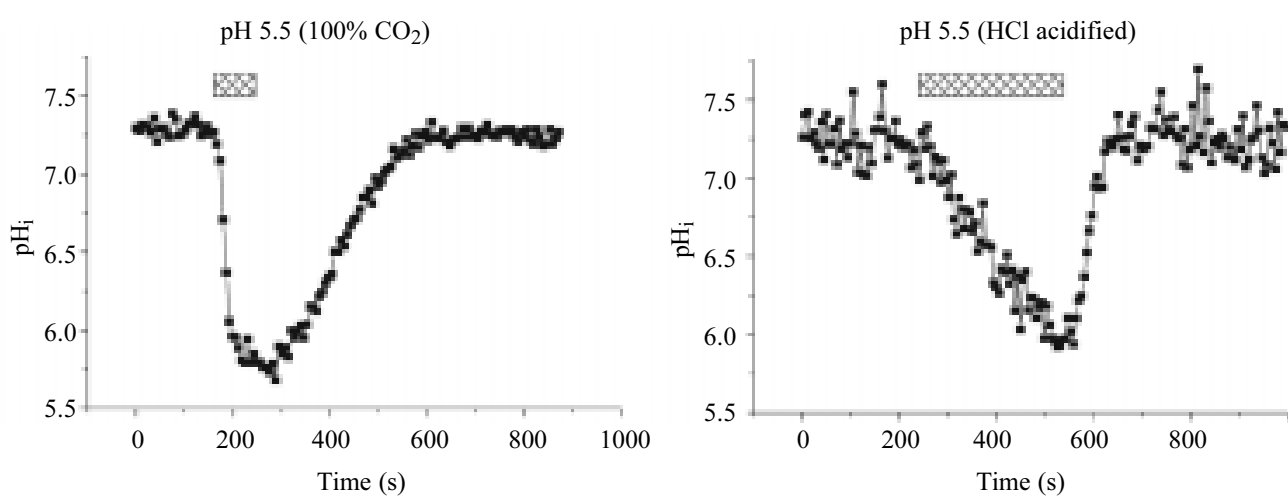

Figure 6 - Acidification-induced uncoupling in pairs of $\mathrm{C} \times 46$ transfected Neuro-2a cells. A, Whole-cell patch recordings of junctional current, $\mathrm{l}_{\mathrm{j}}$, in response to a series of brief alternating $\mathrm{V}_{\mathrm{j}}$ steps of +30 and $-30 \mathrm{mV}$. Comparison of application of $100 \%$ $\mathrm{CO}_{2}$-equilibrated medium (top trace) and $\mathrm{HCl}$-acidified medium (pH 5.5). $\mathrm{CO}_{2}$ application rapidly reduced $I_{j}$ to undetectable levels. Recovery was delayed and only reached $10-15 \%$ of the original value. Application of $\mathrm{HCl}$ acidified medium caused $\mathrm{l}_{\mathrm{j}}$ to decrease slowly and steadily. Recovery began soon after washout and reached $\sim 70 \%$ of the original value. $\mathrm{B}$, The changes in $\mathrm{pH}_{\mathrm{i}}$ in $\mathrm{Cx} 46$ transfected Neuro-2a cells follow the time course of the changes in $\mathrm{gj}$. Application of $\mathrm{CO}_{2}$-equilibrated medium decreased $\mathrm{pH}_{\mathrm{i}}$ to $\sim 5.8$ within $50 \mathrm{~s}$. Recovery was much slower and lasted for almost 300 s. Application of medium acidified to $\mathrm{pH} 5.5$ with $\mathrm{HCl}$ decreased $\mathrm{pH}_{\mathrm{i}}$ steadily from 7.25 to $\sim 6.0$ over $\sim 300 \mathrm{~s}$. Recovery upon washout was complete within $\sim 100 \mathrm{~s}$. Measurement of $\mathrm{pH}_{\mathrm{i}}$ was accomplished using the acidic form of BCECF. Single cells were whole-cell patch clamped with BCECF added to the patch pipette solution. 
Figure 7 - Two recordings from a Neuro-2a cell pair with $\mathrm{I}_{\mathrm{j}}$ in response to $\mathrm{V}_{\mathrm{j}}$ steps of $+25 \mathrm{mV}$. Application of $100 \% \mathrm{CO}_{2}$-equilibrated medium for $25 \mathrm{~s}$ reduced $\mathrm{l}_{\mathrm{j}}$ to undetectable levels (top trace). Recovery was delayed for $-60 \mathrm{~s}$ upon washout, and $\mathrm{I}_{\mathrm{j}}$ increased slowly to $\sim 50 \%$ of the original value. A shorter exposure to $100 \% \mathrm{CO}_{2}(15 \mathrm{~s})$ significantly but not completely reduced $\mathrm{I}_{\mathrm{j}}$ (lower trace). Washout began soon after the initial decline in $\mathrm{I}_{\mathrm{j}}$. Recovery was delayed less with this shorter exposure and was essentially complete $(>90 \%$ ) within $2 \mathrm{~min}$
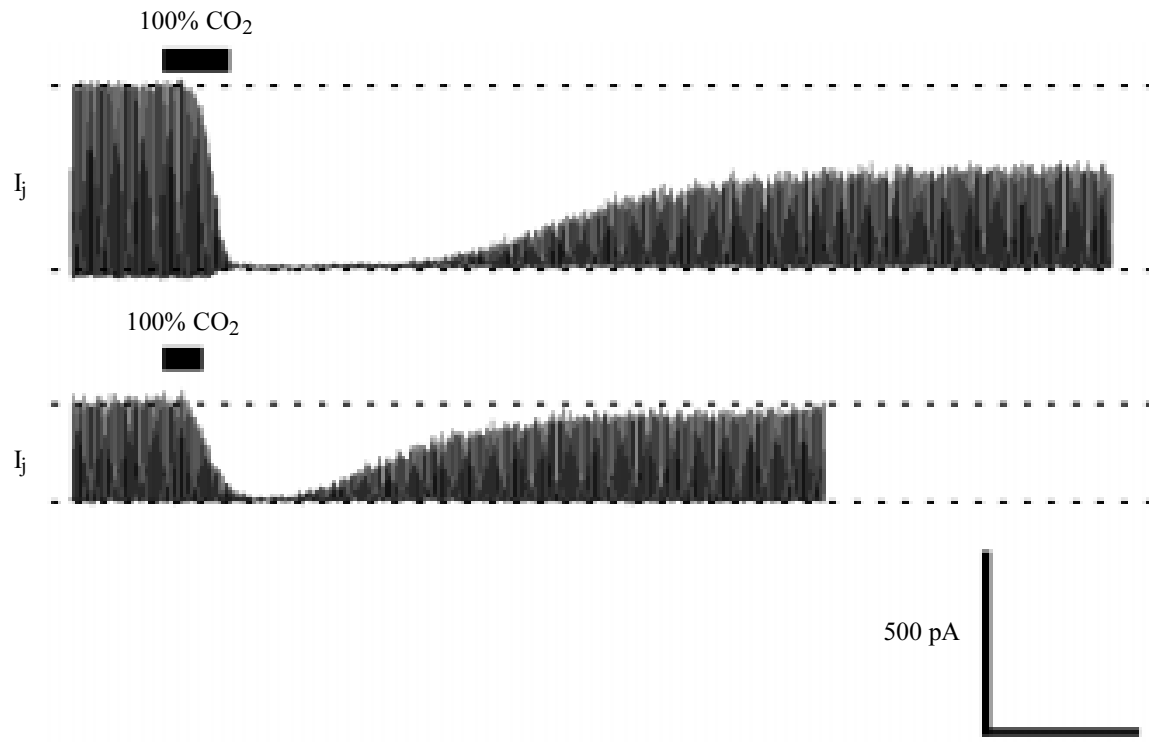

$60 \mathrm{~s}$

$\mathrm{CO}_{2}$ for the first time and in those that had prior exposures to $\mathrm{CO}_{2}$. We conclude that prolonged acidification causes a population of cell-cell channels or hemichannels to enter a nonconducting state from which there is slow or no recovery. We provisionally termed the process of entering this state $\mathrm{pH}$ inactivation (6). The fraction of channels and hemichannels entering the inactivated state increases with the duration of acidification. The remaining fraction recovers rapidly upon washing and we consider this reversible form of $\mathrm{pH}$ regulation to be $\mathrm{pH}$ gating. We have not distinguished whether $\mathrm{pH}$ gating and $\mathrm{pH}$ inactivation are mediated by the same or separate sites of $\mathrm{H}^{+}$action. Nonetheless, both Cx46 hemichannels and cell-cell channels share this property along with a high sensitivity to cytoplasmic $\mathrm{pH}$ and slow gating induced by low $\mathrm{pH}$.

\section{Conclusions}

A variety of attributes related to selectivity, ion fluxes and regulation by chemical uncouplers such as $\mathrm{H}^{+}$, are maintained in both CX46 hemichannels and cell-cell channels. Such conservation of properties suggests that hemichannel structure is largely conserved, whether they are apposed or unapposed. Hemichannels, unlike cell-cell channels, allow examination at the single channel level using techniques widely applied to other membrane channels and receptors and their study will likely routinely accompany studies of connexin structurefunction and regulation. For the most part, functional hemichannels have been observed using the Xenopus oocyte expression system $(3,14-16)$, but there are reports of functional hemichannels in mammalian cells transfected with connexins (17). Support for functional hemichannels in vivo comes from horizontal cells of the teleost retina, where GJs mediate the lateral inhibition of excitatory stimuli in the horizontal cell layer of the outer retina. The connexin expressed in these cells has yet to be identified. Thus, in addition to their utility in studies of cell-cell channels, hemichannels may function as membrane channels, an as yet unexplored role of connexins. 


\section{References}

1. Neyton J \& Trautmann A (1985). Singlechannel currents of an intercellular junction. Nature, 317: 331-335.

2. Veenstra RD \& DeHaan RL (1986). Measurement of single channel currents from cardiac gap junctions. Science, 233: 972974.

3. Ebihara L \& Steiner E (1993). Properties of a nonjunctional current expressed from a rat connexin46 cDNA in Xenopus oocytes. J ournal of General Physiology, 102: 59-74.

4. Paul DL, Ebihara L, Takemoto LJ, Swenson KI \& Goodenough DA (1991). Connexin46, a novel lens gap junction protein, induces voltage-gated currents in nonjunctional plasma membrane of Xenopus oocytes. J ournal of Cell Biology, 115: 1077-1089.

5. Trexler EB, Bennett MV, Bargiello TA \& Verselis VK (1996). Voltage gating and permeation in a gap junction hemichannel. Proceedings of the National Academy of Sciences, USA, 93: 5836-5841.

6. Trexler EB, Bukauskas FF, Bennett MV, Bargiello TA \& Verselis VK (1999). Rapid and direct effects of $\mathrm{pH}$ on connexins revealed by the connexin46 hemichannel preparation. J ournal of General Physiology, 113: 721-742.

7. Bukauskas FF (1999). Inducing de novo formation of gap junction channels. In:
Giaume C \& Bruzzone R (Editors), Methods in Molecular Biology: Connexin Channels. Humana Press Inc., Totowa, NJ (in press).

8. Levitt DG (1999). Modeling of ion channels. J oumal of General Physiology, 113: 789-794.

9. Chen D, Lear J \& Eisenberg B (1997). Permeation through an open channel: Poisson-Nernst-Planck theory of a synthetic ionic channel. Biophysical J oumal, 72: 97-116.

10. Bennett MV \& Verselis VK (1992). Biophysics of gap junctions. Seminars in Cell Biology, 3: 29-47.

11. Bukauskas FF \& Weingart R (1994). Voltage-dependent gating of single gap junction channels in an insect cell line. Biophysical J ournal, 67: 613-625.

12. Moreno $\mathrm{AP}$, Rook MB, Fishman $\mathrm{Gl} \&$ Spray DC (1994). Gap junction channels: distinct voltage-sensitive and -insensitive conductance states. Biophysical J ournal, 67: 113-119.

13. Bukauskas FF \& Peracchia C (1997). Two distinct gating mechanisms in gap junction channels: $\mathrm{CO}_{2}$-sensitive and voltagesensitive. Biophysical J oumal, 72: 21372142.

14. Castro C, Gomez-Hernandez J M, Silander K \& Barrio LC (1999). Altered formation of hemichannels and gap junction channels caused by C-terminal connexin-32 mutations. J oumal of Neuroscience, 19: 37523760.

15. Ebihara L (1996). Xenopus connexin38 forms hemi-gap-junctional channels in the nonjunctional plasma membrane of Xenopus oocytes. Biophysical J oumal, 71: 742748.

16. Ebihara L, Berthoud VM \& Beyer EC (1995). Distinct behavior of connexin56 and connexin46 gap junctional channels can be predicted from the behavior of their hemi-gap-junctional channels. Biophysical J ournal, 68: 1796-1803.

17. Li H, Liu TF, Lazrak A, Peracchia C, Goldberg GS, Lampe PD \& J ohnson RG (1996). Properties and regulation of gap junctional hemichannels in the plasma membranes of cultured cells. J ournal of Cell Biology, 134: 1019-1030.

18. Draber S \& Schultze R (1994). Detection of jumps in single-channel data containing subconductance levels. Biophysical J ournal, 67: 1404-1413.

19. Trexler EB \& Verselis VK (1999). The study of connexin hemichannels (connexons) in Xenopus oocytes. In: Giaume $\mathrm{C} \&$ Bruzzone R (Editors), Methods in Molecular Biology: Connexin Channels. Humana Press Inc., Totowa, NJ (in press). 